\title{
BEM-ESTAR E SANIDADE DE ANIMAIS UTILIZADOS PARA TRAÇÃO ANIMAL NO MUNICÍPIO DE PARNAÍBA, PIAUÍ
}

Severino Cavalcante de Sousa Junior ${ }^{1}$; Karina Rodrigues dos Santos ${ }^{1}$; Gustavo Cardoso Girelli ${ }^{2}$

${ }^{1}$ Professor Doutor, Universidade Federal do Piauí - Parnaíba - PI, Brasil. (sevzoo@yahoo.com.br)

${ }^{1}$ Professora Doutora, Universidade Federal do Piauí - Parnaíba - PI, Brasil.

${ }^{2}$ Discente do Curso de Medicina, Universidade Federal do Piauí - Parnaíba - PI, Brasil.

Recebido em: 02/10/2017 - Aprovado em: 21/11/2017 - Publicado em: 05/12/2017 DOI: 10.18677/EnciBio_2017B8

\begin{abstract}
Existe uma grande quantidade de equídeos utilizados em atividades de tração nas comunidades rurais e em centros urbanos, realizando as mais variadas atividades e convivendo intensamente com seus proprietários e tratadores, os carroceiros. Desta forma, faz-se necessária buscar soluções para importantes questionamentos sobre o bem-estar, tanto do animal como do homem. Nesse sentido, o presente estudo verificou a sanidade e o bem-estar dos animais utilizados para tração no Município de Parnaíba, Piauí. Na coleta de dados foi utilizado formulário semiestruturado abordando os seguintes aspectos: Temperatura, estado nutricional (escore corporal), resposta ao som e movimentos bruscos, frequência urinária e respiratória. A análise dos aspectos físico e nutricional dos animais revelou que 76,3\% (29) demonstraram escore corporal de médio a ideal em relação ao porte físico. $\mathrm{Na}$ avaliação do bem estar em relação a reação ao som 52,6\% (20) manifestaram suspiros, 34,2\% (13) não tiveram nenhuma reação. Os aspectos fisiológicos quanto à frequência urinária, $52,8 \%$ (19) satisfatório e 47,2\% (17) moderado. Com relação a frequência respiratória $39,1 \%$ (15) apresentam movimentos respiratórios acima de $40 \mathrm{rpm}$, $36,8 \%$ (14) entre o 30 e $40 \mathrm{rpm}$ e 18,4\% (7) entre 20 e $30 \mathrm{rpm}$, acima do valor de referência. Em relação ao estado de saúde dos animais 63,2\% (24) constataram ausência de possíveis danos decorrentes da carga de trabalho. O levantamento do bem-estar e sanidade da população equina da cidade de Parnaíba, mostrou que as dificuldades enfrentadas pelos carroceiros estão relacionadas à necessidade de orientações, de como alimentar e cuidar da saúde dos seus animais.
\end{abstract}

RESUMO

PALAVRAS-CHAVE: Bem estar animal, Carroceiros, Equinos.

\section{ANIMALS' WELL-BEING AND HEALTH USED FOR ANIMAL TRACTION IN THE MUNICIPALITY OF PARNAÍBA, PIAUÍ}

\begin{abstract}
There is a large amount of equines used in traction activities in rural communities and in urban centers, performing the most varied activities and interacting closely with their owners and handlers, the cart drivers. Therefore, it is necessary to seek solutions to important questions about the well-being of both animal and man. Thus,
\end{abstract}


the study herein verifies the animals' well-being and health used for traction in the municipality of Parnaíba, Piauí state. At the data collection, a semi-structured questionnaire was used approaching the following aspects: Temperature, nutritional state (body index), response to sound and abrupt movements, urinary and respiratory frequency. The analysis of the physical and nutritional status of the animals revealed that $76.3 \%$ (29) demonstrated a score index of medium ideal in relation to the physical size. In the evaluation of the animal's well-being regarding sound $52.6 \%$ (20) expressed sighs, 34.2\% (13) had no reaction. The physiological aspects in terms of the urinary frequency, $52.8 \%$ (19) Satisfactory and $47.2 \%$ (17) moderate. 39.1\% (15) feature respiratory movements above $40 \mathrm{rpm}, 36.8 \%$ (14) between 30 and $40 \mathrm{rpm}$ and 18,4\% (7) between 20 and $30 \mathrm{rpm}$ above the reference value. Concerning the animals' health status $63,2 \%(24)$ found no possible damage arising from the work load. The survey on the equine population's well-being and health in the municipality of Parnaiba, shows that the difficulties faced by the cart drivers are related to the need for guidelines of how to feed and care for the health of their animals.

KEYWORDS: Cart drivers, Equines, Animal's well-being.

\section{INTRODUÇÃO}

Desde as antigas civilizações há relatos do uso de animais para benefício humano. Entre os animais utilizados para transporte a família Equídae é de grande relevância na história da humanidade. Atualmente, os equinos ainda são utilizados em atividades de tração em comunidades rurais e em centros urbanos, realizando as mais variadas atividades, que incluem coleta de materiais desejáveis e inservíveis para a reciclagem e transporte de entulho. $O$ equídeo de tração, desde a domesticação, é tido como ferramenta indispensável para as pessoas que sobrevivem do trabalho humano associado ao trabalho animal. Utilizado para diversas funções na sociedade, mas geralmente exigido acima de seus limites naturais, ou do seu bem estar (BOMFIM et al., 2017).

No Brasil, segundo dados do Instituto Brasileiro de Geografia e Estatística de 2011, a população de equídeos era de 7.752.276, destes 5.508.546 Equus caballus (o IBGE refere-se como equíneos), 974.532 Equus asininos e 1.269.198 Equus muares. No Piauí do total de 258.058 equídeos, sendo 109.936 Equus caballus, 119.054 Equus asininos e 29.068 Equus muares. Destaca-se a população de asininos que representa $12,2 \%$ da população nacional, sendo a $3^{\text {a }}$ maior do país. É importante considerar que os dados do censo levam em consideração, principalmente, a população ligada a atividades agropecuárias destes animais, é de se supor que os equídeos de tração, muitas vezes, não foram contabilizados nestes dados. Desta forma, a população total dessa família de animais é maior (IBGE, 2011).

Amaral et al. (2015), relatam que a pobreza é um problema de cunho mundial e de difícil resolução, principalmente em relação aos países em desenvolvimento. A atividade de carroceiro representa uma fonte de renda, ainda muito comum, no Brasil e no mundo. No entanto, esta relação de trabalho nem sempre encontra-se em harmonia. Dória et al. (2016) descrevem que é frequente encontrar equinos utilizados em trabalho de tração em condições precárias de nutrição e higidez. Um estudo feito por Chaves et al. (2014), na Cidade de São Luís (MA) apontou que a carga transportada diariamente por esses animais pode ultrapassar $500 \mathrm{Kg}$, no entanto o manejo alimentar e escore corporal, muitas vezes, são incompatíveis com a atividade exercida. Outros trabalhos relacionados com carroceiros, avaliação 
clínica e/ou de bem-estar dos seus animais de tração foram realizados como os de: Hammerschmidt (2012), Paz et al. (2013), Schade et al. (2013) e Godoy et al. (2014). Entretanto, ao considerar a grande população de animais utilizados como força de tração e carroceiros, esta área de pesquisa é ainda pouco investigada e discutida na atualidade.

Segundo o levantamento epidemiológico feito por Godoy et al. (2014) em Pirassununga (SP), o principal motivo dos proprietários de equídeos de carroça procurarem o veterinário foi devido a alterações no sistema musculoesquelético. Dentre as doenças de maior ocorrência observadas destaca-se adenite equina e afecções do trato gastrintestinal. A procura para diagnóstico de gestação também foi frequente. Foi constatado no mesmo estudo que a falta de conhecimento acerca do correto manejo dos animais pode ser por vários motivos, e com relação a alterações de diversas naturezas, tais como fadiga muscular, doenças articulares, alterações do casco, dentre outras.

A falta de informação dos carroceiros acerca do tratamento adequado de seus animais equinos pode resultar em desequilíbrios nutricionais em termos de qualidade e quantidade, tornando os animais mais susceptíveis à doenças, além de um menor rendimento no trabalho de tração, podendo resultar em lesões e até na morte dos animais. Levando-se em consideração a elevada quantidade de pessoas que utilizam animais para atividades de tração, há muito a ser estudado e pesquisado, existem ainda lacunas na literatura que visem identificar o bem-estar dos carroceiros associados com bem-estar e sanidade dos animais.

Desta forma, visando conhecer as condições de trabalho, sanidade e bemestar dos animais utilizados na tração das carroças, o presente estudo teve como objetivo verificar a sanidade e o bem-estar dos animais utilizados para tração do Município de Parnaíba, Piauí.

\section{MATERIAL E MÉTODOS}

Etogramas específicos foram desenvolvidos e utilizados para este estudo visando compreender a realidade dos carroceiros e dos animais de tração. Foi realizada uma observação direta, sem período de adaptação, considerando que estes animais habitualmente já convivem com uma grande quantidade de pessoas diferentes e em ambiente estressantes como ruas e avenidas públicas em seu dia a dia.

A pesquisa respalda-se na resolução 196/96 do Conselho Nacional de Pesquisa que trata das questões éticas relacionadas à pesquisa com seres humanos, o presente estudo foi devidamente aprovado pelo Comitê de Ética em Pesquisa da Universidade Federal do Piauí, Campus Ministro Reis Velloso sob o número de Protocolo 266/16,

Vale salientar que a pesquisa foi realizada no período de agosto de 2015 a junho de 2016, foram acompanhados 37 carroceiros e 38 equídeos em atividade. $\mathrm{Na}$ coleta de dados foi utilizado formulário semiestruturado abordando os seguintes aspectos: Estado nutricional (escore corporal); atitude do animal em relação ao som; atitude do animal com relação aos movimentos; tempo de reação a estímulos; frequência urinária; frequência respiratória; qual o estado de saúde do animal. De maneira geral existem marcas, cicatrizes, feridas, sarnas, carrapatos ou outras, que possam levar a impressão ou conclusão de maus tratos; o animal apresenta sinais de cansaço, aparência fraca, aprumos fracos ou sinais de alguma deficiência; foi observada a presença de carrapatos nas orelhas, barriga, traseiro e peito; rigidez 
muscular, dentes cerrados, apatia e a não resposta a estímulos; observou-se mucosa ocular, pelos arrepiados e outros.

Em relação ao bem-estar dos animais foi estimado através das medidas da frequência cardíaca, frequência respiratória, com a observação e contagem dos movimentos do flanco do animal durante um minuto ( $\mathrm{mov} / \mathrm{min}$.), tendo como valores de referências normais 12-24 movimentos por minutos ( $\mathrm{mpm}$ ) em cavalos adultos, segundo Savage (2016), e temperatura corporal através de um exame clínico de cada animal.

Após a aplicação dos formulários, preenchidos pelos pesquisadores em entrevistas com os carroceiros, os dados foram tabulados, posteriormente foram realizadas análises de consistências e de estatísticas descritiva. A média aritmética e porcentagens das amostras foram obtidas através de cálculos no programa Excel (2016).

\section{RESULTADOS E DISCUSSÃO}

Foram cadastrados 38 equídeos de tração durante o período do estudo, sendo: $36,8 \%$ (14) cavalos; $21,1 \%$ (08) jumentos e; $42,1 \%$ (16) híbridos. A média de idade dos animais foi de 6,9 anos entre os cavalos, 4,7 anos jumentos e 7,9 anos entre os híbridos (mulas e burros). Em relação ao sexo, registrou-se que cerca de $60 \%$ dos equídeos eram machos, nos cavalos houve predominância do sexo masculino com cerca de 3/4 (10 animais) do total, entre os jumentos registrou-se um número igual de indivíduos de cada sexo, já no caso dos híbridos ocorreu uma inversão, há uma razão de 3/5 (10 animais) de fêmeas (mulas) em relação aos machos (burros).

A análise dos aspectos físico e nutricional dos animais (Tabela 1) revelou que $76,32 \%$ (29) demonstraram escore corporal considerado de médio a ideal em relação ao porte físico. Porém, 15,79\% (6) apresentam magreza em função da má nutrição fornecida ou do excesso de trabalho imposto ao animal, demonstrando que quando há escassez de alimento ou o mau fornecimento nutricional são prejudiciais, estes devem ser acompanhados de informações nutricionais para que o manejo seja satisfatório uma vez que a nutrição é um fator importante responsável pela total capacidade de trabalho do animal, tal como informação referente ao bem estar dos animais, para evitar traumas e lesões por excesso de trabalho resultados semelhantes foram apresentados por Filho et al. (2004) e Sangioni et al. (2016), que concluíram que a alimentação dos animais de carroceiro está aquém da necessária, e que mais de $58 \%$ dos animais apresentavam aspecto de magreza.

TABELA 1: Avaliação física, comportamental e fisiológica dos equídeos utilizados para tração no município de Parnaíba, Piauí.

\begin{tabular}{lc}
\hline Estado nutricional (escore corporal) & $\mathbf{n}(\%)$ \\
\hline Caquético & $0(0)$ \\
Magro & $6(15,8)$ \\
Média Ideal & $29(76,3)$ \\
Gordo & $3(7,9)$ \\
Obeso & $0(0)$ \\
\hline TOTAL & $\mathbf{3 8 ( 1 0 0 )}$ \\
\hline Atitude do animal com relação ao som & $\mathbf{n}(\%)$ \\
\hline Grito & $0(0)$ \\
Relincho & $5(13,2)$ \\
Ronco & $0(0)$ \\
\hline
\end{tabular}

ENCICLOPÉDIA BIOSFERA, Centro Científico Conhecer - Goiânia, v.14 n.26; p.87 


\begin{tabular}{lc}
\hline Rugido & $0(0)$ \\
Suspiro & $20(52,6)$ \\
Nenhuma reação & $13(34,2)$ \\
\hline TOTAL & $\mathbf{3 8 ( 1 0 0 )}$ \\
\hline Atitude do animal em relação aos movimentos (orelha) & $\mathbf{n}(\%)$ \\
\hline Inclinação aguda para frente & $25(65,8)$ \\
Caídas para o lado & $2(5,3)$ \\
Abaixadas e voltadas para trás & $11(28,9)$ \\
\hline TOTAL & $\mathbf{3 8 ( 1 0 0 )}$ \\
\hline Tempo de reação a um estímulo & $\mathbf{n}(\%)$ \\
\hline Lento & $1(2,6)$ \\
Moderado & $9(23,7)$ \\
Rápido & $28(73,7)$ \\
\hline TOTAL & $\mathbf{3 8 ( 1 0 0 )}$ \\
\hline Frequência urinária do animal & $\mathbf{n}(\%)$ \\
\hline Insatisfatória & 0 \\
Moderada & $17(44,7)$ \\
Satisfatória & $19(50,0)$ \\
Não informada & $2(5,3)$ \\
\hline TOTAL & $\mathbf{3 8 ( 1 0 0 )}$ \\
\hline Frequência respiratória & $\mathbf{n}(\%)$ \\
\hline Entre 20 e 30 rpm & $14(36,8)$ \\
Entre 30 e 40 rpm & $7(18,4)$ \\
Acima de 40 rpm & $15(39,5)$ \\
Não informado & $2(5,3)$ \\
\hline TOTAL & $\mathbf{3 8 ( 1 0 0 )}$ \\
\hline Fonte Os autorita
\end{tabular}

Fonte: Os autores, (2017).

$\mathrm{Na}$ avaliação do bem estar por meio da perceptiva da reação do animal em relação ao som (Tabela 1), 52,6\% manifestaram suspiros, 34,2\% não tiveram nenhuma reação e $13,2 \%$ emitiram relinchos. Tal resultado era esperado, pois os animais já estavam adaptados ao ambiente e às condições de trabalho que lhe são impostas. Na avaliação da atitude do animal com relação ao movimento das orelhas, verificou-se que 65,8\% apresentaram inclinação aguda para frente, $28,9 \%$ mantiveram-nas abaixadas e voltadas para trás e $5,3 \%$ apresentaram orelhas caídas para o lado, esta informações indicam temperamento calmo e atento ao que esta ocorrendo em torno do animal, mas sem manifestar estresse. Com relação ao tempo de reação a estímulos, observou-se que $73,7 \%$ responderam de forma rápida, $23,7 \%$ tiveram resposta moderada e $2,6 \%$ demonstraram lentidão na resposta. Os resultados sobre a capacidade perceptiva dos animais demonstrou-se satisfatória, em condições adequadas de bem-estar e em resposta aos testes de estresse aplicados de acordo Grandin e Johnson (2010) os estímulos podem causar reações diferentes nos animais, como medo raiva e fuga, porém quando os animais estão adaptados, estes passam a não reagirem.

Os aspectos fisiológicos dos animais (Tabela 1) também foram avaliados quanto à frequência urinária diária, sendo esta informação obtida segundo relato dos proprietários (carroceiros), como satisfatório $50,00 \%$ e moderado $44,7 \%$ e $5,3 \%$ considerou frequência insatisfatória, segundo Silveira et al., (2012) a frequência 
urinária esta relacionada a alterações das frequências respiratória e cardíaca e da temperatura retal em equinos.

A análise dos dados revelou ainda que, 39,1\% (15) animais apresentaram movimentos respiratórios acima de 40 rpm, 36,8\% (14) entre 30 e 40 rpm e 18,4\% (7) entre 20 e $30 \mathrm{rpm}$, ou seja, acima do valor de referência, isso pode ser explicado pelo fato das entrevistas terem sido realizadas nos intervalos entre as atividades dos animais, sendo que em grande parte dos casos os animais ainda estavam encaixados junto à carroça. Porém, tais alterações podem ser resultado de situações de estresse causado pela longa contenção ou pela presença de dor decorrente de afecções do sistema locomotor devido ao excesso de peso, carregado pelos animais, ou pelo excesso de horas trabalhadas, resultados semelhantes, em equinos, foram relatados por Fonseca et al. (2014a) e Fonseca et al. (2014b), em trabalhos com animais submetidos a esforço físico em vaquejadas, as características foram colhidas antes e após o esforço físico e foram verificadas alterações dos parâmetros fisiológicos dos animais que podem comprometer a saúde dos animis.

TABELA 2: Quantidades absolutas e relativas da avaliação de equídeos utilizados para tração no município de Parnaíba, Piauí.

\begin{tabular}{lcc}
\hline Critérios & Porcentagem (\%) & N \\
\hline Parasitismo ou lesões na pele & & 12 \\
\hline Apresentam & 31,57 & 24 \\
Não apresentam & 63,15 & 02 \\
Não informado & 5,28 & . \\
\hline
\end{tabular}

Sinais de cansaço, aparência fraca, apromos fracos ou deficiência

\begin{tabular}{lcc}
\hline Apresentam & 18,4 & 07 \\
Não apresentam & 63,2 & 24 \\
Não informado & 18,4 & 07 \\
\hline \multicolumn{1}{c}{ Sinais de rigidez muscular, dentes cerrados ou apatia } \\
\hline Apresentam & 7,9 & 03 \\
Não apresentam & 68,4 & 26 \\
Não informado & 23,7 & 09 \\
\hline \multicolumn{2}{c}{ Sinais de estresse, pelos arrepiados e irritação na mucosa ocular } \\
\hline Apresentam & 63,2 & 24 \\
Não apresentam & 26,3 & 10 \\
Não informado & 10,5 & 04 \\
\hline \multicolumn{2}{c}{ Carrapatos nas orelhas, barriga, traseiro e peito } \\
\hline Apresentam & 7,9 & 03 \\
Não apresentam & 71,0 & 27 \\
Não informado & 21,1 & 08 \\
\hline
\end{tabular}

Fonte: Os autores, (2017).

Em relação ao estado de saúde do animal, 63,15\% (24) dos animais não apresentaram qualquer sinal externo de parasitismo e/ou lesões de pele ou possíveis danos decorrentes da carga de trabalho (Tabela 2), podendo ser percebidos por sinais de cansaço com aprumos fracos ou sinais de alguma deficiência na locomoção, ou até mesmo na aparência fraca do animal após a execução do trabalho e $63,20 \%$ (24) apresentam esses sinais, assim como também $18,4 \%$ (7) não informaram nenhum sinal do estado de saúde do animal, resultados semelhantes aos apresentados por Chaves et al. (2014) e Dória et al. (2016) que muitos dos diagnósticos de ausência de hemoparasitose por exame hematológico e ENCICLOPÉDIA BIOSFERA, Centro Científico Conhecer - Goiânia, v.14 n.26; p.89 2017 
ou esfregaço sanguíneo são errôneos, devido à baixa sensibilidade da técnica e podem repercutir em falha no tratamento com consequente disseminação dos hemoparasitos e das hemoparasitoses.

Além desses sinais que podem evidenciar sobrecarga de trabalho, 7,9\% (3) dos animais apresentaram sinais à rigidez muscular, dentes cerrados e até mesmo apatia, 68,4\% (26) não apresentaram esses sinais (Tabela 2). Em relação aos sinais de estresses, 63,2\% (24) dos animais apresentaram pelos arrepiados e irritação na mucosa ocular e 26,3\% (10) não apresentaram esses sinais, pois segundo Bomfim et al. (2017) a sobrecarga pode ser finte de adoecimento e estresse dos animais.

Com relação aos cuidados com os animais, $89,2 \%$ dos carroceiros fornecem sombra e água aos animais durante os intervalos de trabalho e apenas quatro dos entrevistados (10,8\%) não adotam essa prática (Figura 1).

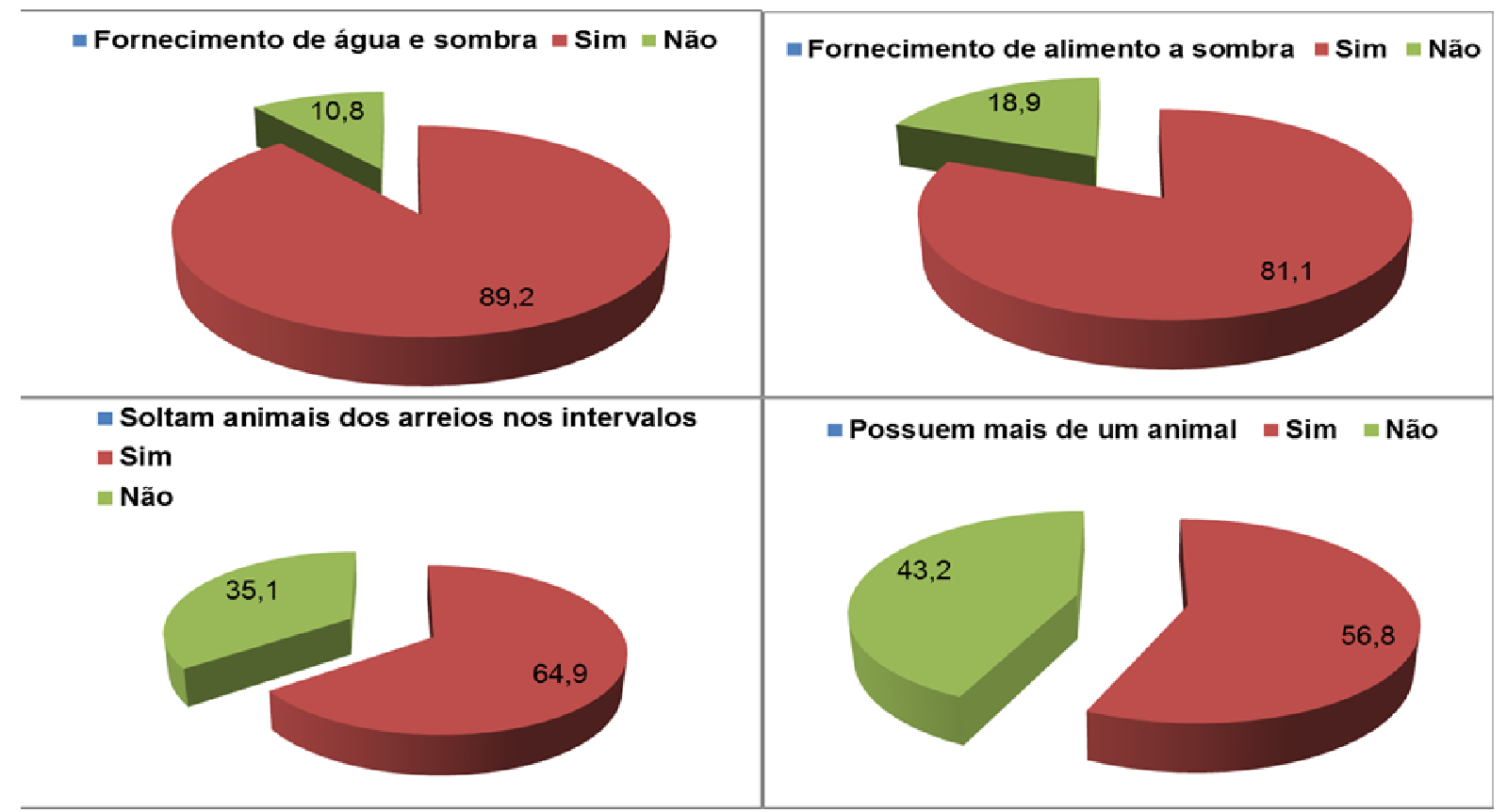

FIGURA 1: Fornecimentos de água a sombra, fornecimento de alimento a sombra, soltam os animais dos arreios nos intervalos dos trabalho, e se possuem mais de um animal para tração das carroças da cidade de Parnaíba, Piauí.

Fonte: Os autores (2017)

Também foi observado que $81,1 \%$ dos entrevistados alimentam o animal nos intervalos e apenas 18,9\% não executam essa prática. Nesse sentido, Anjos e Leme (2014) afirmam que a ingestão de pequenas e frequentes quantidades de alimentos é um importante componente do bem-estar dos cavalos. Dos carroceiros entrevistados, $64,9 \%$ soltam os animais dos arreios durante os intervalos e $35,1 \%$ não fazem esse procedimento, resultados diferentes dos apresentados por Filho et al. (2004) e Sangioni et al. (2016) que relataram oferta de alimentação inadequada aos animais, baixos escores corporais e falta de conhecimentos e atitudes que favorecem o bem estar dos animais.

Outro dado que merece destaque é que $56,8 \%$ entrevistados possuem outros animais para dividir o serviço de tração das carroças. Este fato chamou a atenção por demonstrar que a maioria dos carroceiros entrevistados demonstram certa preocupação com a saúde do animal, reduzindo a jornada de trabalho e também preocupação com o rendimento da atividade, de acordo com o exposto por 
Hammerschmidt (2012) e Godoy et al. (2014). A grande maioria dos entrevistados $(64,9 \%)$ revelou que há preocupação com o estado de saúde dos equídeos, porém $35,1 \%$ nunca levaram os animais ao veterinário, o que demonstra a dificuldade financeira que essa classe sofre para a aquisição de cuidados médicos aos seus equídeos, $37,5 \%$ dos que se preocupam com seus animais os levaram mais de três vezes ao veterinário, ainda segundo Dória et al. (2016), a sanidade tem sido mencionada como importante causa de danos à sanidade animal com comprometimento da função equina exercida pelos animais.

Verificou-se que $81,3 \%$ dos entrevistados relataram que a doença mais frequente nos animais é diarréia, enquanto que 12,5\% disseram ser resfriado das vias nasais e 6,2\% citaram as doenças causadas por parasitas. Os tratamentos oferecidos pelos carroceiros aos animais são à base de medicamentos (48,7\%), vacina $(27,0 \%)$, cuidados caseiros $(10,8 \%)$ e $13,5 \%$ usam outros tipos de tratamentos. Através dos relatos, muitos carroceiros não procuram os médicos veterinários, talvez por acreditarem que possuem conhecimentos necessários para cuidar da saúde de seu animal com tratamentos caseiros e/ ou até mesmo medicar os animais sem prescrição do veterinário, além das dificuldades financeiras que essas pessoas enfrentam, dados semelhantes aos publicados por Chaves et al. (2014) e Dória et al. (2016), em seus trabalhos, onde os entrevistados não apresentavam o hábito de levarem seus animais ao médico veterinário, e muito menos, de buscarem informações sobre sanidade, alimentação e outras questões importante para a saúde e bem estar animal.

No reconhecimento geral do estado de saúde física, diagnosticado com a análise da presença de parasitismo (carrapatos e sarnas), lesões na pele (feridas, cicatrizes) que possam comprovar maus tratos, $57,1 \%$ (24) não apresentaram nenhuma dessas características, 28,6\% (12) apresentam tais sinais e 14,3\% (6) não informado (Tabela 2), resultados semelhantes aos obtidos por Hammerschmidt (2012) e Chaves et al. (2014), que afirmaram em seus trabalhos, que o ambiente é um dos fatores que oferecem maiores ricos ao bem estar animal e a sanidade também.

O parasitismo por carrapatos nas regiões das orelhas, barriga, traseiro e peito, foi observado em $71,0 \%$ (27), mas sem danos visíveis, $21,1 \%$ (8) com danos e $7,9 \%$ (3) não foi possível a visualização das áreas do corpo dos animais (Tabela 2). Animais com comprometimento sanitário, desnutrido, que realizam esforços excessivos e ao mesmo tempo não recebem imunização preventiva e que sofrem constantes ferimentos e estresse estão mais sujeitos a desenvolverem enfermidades frequentes e uma redução na expectativa de vida.

\section{CONCLUSÃO}

Foi possível constatar por meio deste trabalho que, o bem estar e a sanidade dos animais utilizados para tração, da Cidade de Parnaíba, estado do Piauí, foram comprometidos por excessos como; estresse físico (excesso de horas trabalhadas,ou excesso de peso das carroças), excesso de exposição ao sol, hidratação deficiente, alimentação insuficiente e inadequada, entre outros.

A utilização de equídeos para a tração de carga constitui-se numa prática socialmente aceita, desde que, respeitadas as necessidade e características dos animais. É de grande relevância que as informações sobre manejo de animais de tração sejam acessíveis às pessoas que praticam tal atividade. Desta forma, seria de grande valia um guia redigido em linguagem simples e acessível, tendo como 
público-alvo os carroceiros, visando orientá-los sobre os cuidados básicos a serem tomados com os seus animais.

Essas informações poderiam melhorar o bem-estar e sanidade dos animais, sua produtividade e, consequentemente, a rentabilidade dos serviços prestados e as condições socioeconômicas dos carroceiros.

\section{REFERÊNCIAS}

AMARAL, R. F.; CAMPOS, K. C.; LIMA, P. V. P. S. Distribuição da pobreza no estado do Ceará: uma abordagem multidimensional. Interações, Campo Grande, v. 16, n. 2, p. 327-337, 2015. Disponível em: < http://dx.doi.org/10.1590/151870122015208>. DOI: 10.1590/1518-70122015208

ANJOS, A. N. A.; LEME, D. P. Práticas de manejo alimentar de equinos estabulados em Santa Catarina. Revista Acadêmica: Ciências Agrárias e Ambientais, Curitiba, v. 12, n. 2, p. 113-120, 2014. Disponível em: <http://dx.doi.org/10.7213/academica.12.02.AO04>.

DOI:10.7213/academica.12.02.AO04.

BOMFIM, M. M.; SATTIN, W. R.; CARVALHO, S. F.; GOBESSO A. A. O.; DÓRIA R. S. G.; LEITE-DELLOVA D. C. A. Physical and electrocardiographic evaluation of horses used for wagon traction. Arquivo Brasileiro de Medicina Veterinária e Zootecnia, Belo Horizonte, vol.69 n.2, 2017. Disponível em: <http://dx.doi.org/10.1590/1678-4162-9248>. DOI:10.1590/1678-4162-9248.

ChAVES, N. P.; BEZERRA D. C,; SANTOS, H. P. ; PEREIRA, H. M.; GUERRA, P. C. G.; SILVA, A. L. A. Ocorrência e fatores de risco associados à identificação da anemia infecciosa equina em equídeos de tração. Ciência animal brasileira. v.15 n.3 Goiânia, 2014. Disponível em: <http://dx.doi.org/10.1590/18096891v15i318395>. DOI: 10.1590/1809-6891v15i318395

DÓRIA, R. G. S.; PASSARELLI, D.; CHEQUER, T. N.; REGINATO, G. M.; HAYASAKA, Y. B.; et al. Investigação clínica e comparação do esfregaço sanguíneo e PCR para diagnóstico de hemoparasitas em equinos de esporte e tração (carroceiros). Pesquisa Veterinária Brasileira, Rio de Janeiro, v.36 no.8, 2016. Disponível em: < http://dx.doi.org/10.1590/S0100-736X2016000800008>. DOI: 10.1590/S0100-736X2016000800008

FILHO, J. M. S.; PALHARES, M. S.; MARANHÃO, R. P. A.; REZENDE, H. H. C.; MELO, U. P. Manejo Alimentar dos Animais de Tração da Regional Pampulha - Belo Horizonte. Anais do $2^{\circ}$ Congresso Brasileiro de Extensão Universitária. Belo Horizonte. 2004. Disponível em: < https://www.ufmg.br/congrext/Desen/Desen16.pdf >. Acesso em: 23 de setembro de 2017.

FONSECA, W. J. L.; BARROS JUNIOR, C.P.; FONSECA, W. L.; LUZ, C, S. M.; OLIVEIRA, A. M.; ARAUJO, A. C.; SOUSA JÚNIOR, S. C. S. Características termorreguladoras de equinos submetidos a competições de Vaquejada. Journal of Animimal Behaviour Biometeorology v.2, n.2, p.43-46 2014a. Disponível em: < http://revistas.bvs-vet.org.br/jabb/article/view/32059 >. $\quad$ DOI: DOI: http://dx.doi.org/10.14269/2318-1265.v02n02a02. 
FONSECA, W. J. L.; LUZ, C, S. M.; FONSECA, W. L.; TERTO e SOUSA, G.G.; SOUSA, D.J .A.; SOUSA JÚNIOR, S. C. S. Physiological Parameters in the Equine Competitions Rodeo Cow in the Southern State of Piaui, Brazil. Journal of Agricultural Science; v.6, n.5; 2014b. Disponível em: < http://revistas.bvsvet.org.br/jabb/article/view/32059 >. DOI: http://dx.doi.org/10.5539/jas.v6n5p80.

GODOY, D. I. C.; PRADO FILHO, R. R.; REGINATO, G. M.; HAYASAKA, Y. B.; FANTINATO NETO, P.; DÓRIA, R. G. S. Projeto Carroceiro FZEA-USP. Revista Cultura e Extensão. USP, São Paulo, n. 11, p.123-135, mai/2014. <http://dx.doi.org/10.11606/issn.2316-9060.v11i0p123-135>.

10.11606/issn.2316-9060.v11i0p123-135

GRANDIM, T.; JOHNSON, C. Bem estar dos animais: Proposta de uma vida melhor para todos os bichos. 1 ed. Rio de Janeiro: Editora ROCCO, 2010.

HAMMERSCHMIDT, J. Desenvolvimento e aplicação de perícia em bem-estar animal. 2012. Dissertação (Mestrado em Ciências Veterinárias) - Universidade Federal do Paraná, Paraná. 2012. Disponível em: <http://acervodigital.ufpr.br/bitstream/handle/1884/27748/R\%20-\%20D\%20\%20HAMMERSCHMIDT\%2c\%20JANAINA.pdf?sequence=1\&isAllowed=y>

IBGE. Instituto Brasileiro de Geografia e Estatística, 2011. Disponível em: <http://www.ibge.gov.br/home/estatistica/economia/ppm/2011/default_pdf.shtm>

PAZ, C. F. R.; PAGANELA, J. C.; OLIVEIRA, D. P.; FEIJÓ, L. S.; NOGUEIRA, C. E. W. N. Padrão biométrico dos cavalos de tração da cidade de Pelotas no Rio Grande do Sul. Ciência animal brasileira, Goiânia, v.14, n.2, 2013. Disponível em: <http://dx.doi.org/10.5216/cab.v14i2.13078>. DOI:10.5216/cab.v14i2.13078

SAVAGE, C.J. Respiratory Work-up in horses. In: International Congress of World Equine Veterinary Association-WEVA, 10 $0^{\text {th }}, 2008$, Moscow, Russia. Disponível em: <www.ivis.org>. Acesso em: 20 de Junho de 2016.

SCHADE, J.; BALDISSERAL, R.; PAOLINI, E.; FONTEQUEL, J. H.; Biometria do equilíbrio podal em equinos de tração pertencentes ao Programa de Extensão "Amigo do Carroceiro" do Centro de Ciências Agroveterinárias da Universidade do Estado de Santa Catarina no município de Lages/SC, Brasil. Ciência Rural, Santa Maria, v.43 n.3, 2013. Disponível em:

<http://dx.doi.org/10.1590/S0103-84782013000300013>. DOI: $10.1590 / S 0103-$ 84782013000300013

SILVEIRA, C. O.; FILHO, J. D. R.; CRUZ, A. L.; MENESES, R. M.; DANTAS,W. M. F.; GUIMARÃES, J. D. Avaliação de equinos submetidos à hidratação enteral com soluções eletrolíticas isotônicas contendo diferentes fontes de energia e cálcio. Archives of Veterinary Science, v.17, n.1, p.22-31, 2012. Disponível em: < http://revistas.ufpr.br/veterinary/article/view/22640>.DOl:http://dx.doi.org/10.5380/avs .v17i1.22640 


\section{ANEXO I - FORMULÁRIO DO ANIMAL}

\section{Perfil sanitário e bem-estar dos animais utilizados para tração do Município de Parnaíba, Piauí}

\begin{tabular}{|l|l|}
\hline Nome do proprietário: & RG do proprietário: \\
\hline CPF do proprietário: & Idade do animal: \\
\hline Sexo do animal: $\square$ Macho $\square$ Fêmea & Raça: \\
\hline
\end{tabular}

1. Estado nutricional (escore corporal)?

( ) Caquético ou emaciado ( ) Magro ( ) Médio ou ideal ( ) Gordo ( ) Obeso

( ) Outro Qual?

2. Atitude do animal com relação ao som?

( ) Grito ( ) Relincho ( ) Ronco ( ) Rugido ( ) Suspiro ( ) Tranquilo

( ) Outro Qual?

3. Atitude do animal com relação aos movimentos (orelhas)?

( ) Inclinação aguda para frente ( ) Abaixadas e voltadas para frente

( ) Inclinação aguda para trás ( ) Abaixadas e voltadas para trás

( ) Caídas para o lado

( ) Outro Qual?

4. Tempo de reação a estímulos?
( ) Lento
( ) Moderado
( ) Rápido

5. Qual a temperatura corporal? ${ }^{\circ} \mathrm{C}$

6. Qual a frequência urinária do animal?
( ) Insatisfatório
( ) Moderado
( ) Satisfatório

7. Qual a frequência respiratória?, rpm.

8. O bem-estar dos animais poderá ser estimado através das medidas da frequência cardíaca, frequência respiratória e temperatura corporal?
( ) Sim
( ) Não

9. Qual o estado de saúde do animal. De maneira geral existem marcas, cicatrizes, feridas, sarnas, carrapatos ou outras, que possa levar a impressão ou conclusões de maus tratos?
( ) Sim
( ) Não

10. O animal apresenta sinais de cansaço, aparência fraca, apromos fracos ou sinais de alguma deficiência? 
( ) $\operatorname{Sim} \quad$ ( ) Não

11. Observar a presença de carrapatos nas orelhas, barriga, traseiro e peito.

( ) Presente Onde?

( ) Ausente

12. Observar rigidez muscular, dentes cerrados, apatia e não resposta a estímulos.
( ) Sadio
( ) Debilitado
( ) Outro Qual?

13. Observar mucosa ocular, pelos arrepiados, e outros.
( ) Normal
( ) Debilitado
( ) Outro(s) Qual(is)? 